\title{
The Effect of Liquidity on Stock Returns: An Evidence From Pakistan
}

\author{
Nasir Akram
}

\begin{abstract}
This study aim to elucidate the association among liquidity and stock return. Ask-bid spread was used as a proxy variable to measure the liquidity. Data was taken from 10 listed companies listed on Karachi stock exchange from 2005 to 2012. Two stage regression was applied to scrutinize the data. The outcomes concluded that there is negative association among liquidity and stock return. These results are supported with (Pereira \& Zhang, 2010). The main limitation of this study was time constraint so that we only incorporated ten companies. For future researcher, impact of excess return on stock sensitivity with vacation of collective liquidity can be studied.
\end{abstract}

Key words: Liquidity, Ask-bid Spread, Excess return.

\section{Introduction}

From the last two decades, after the publication of Amihud and Mendelson (1986) there were number of studies conducted on relationship of stock return and liquidity on different countries. But all of them came up with mixed results. Relationship of liquidity and stock returns have become an interested topic among research after 1986 many researcher like,Gottesman (2000), Brenan and Subramanyam (1996), and Pastor and Stambaugh (2003), all of them concluded with positive (negative) relation with stock returns and variety of illiquidity (liquidity) measures.

Liquidity is one of the imperative characteristic of financial market and considerably important for investment plans and financial assets. Liquidity is the ability of stocks to be traded in the market with lesser price spread and in minimum time. Empirically there are three aspects of liquidity that are investigated; these are depth, cost of tightness and resiliency. The first cost estimates the leeway immersion of large size order. Second cost is calculated by ask-bid spread and estimate the extra cost bore by aggravated investor.Last but not the least, third cost is measure the approximate delay of prices to reach the breakeven point after deviation by liquidity tremor. Deficiency of liquidity can cause the negative effect on stock prices. Whereas, previous literature suggests that transaction cost, liquidity and market capacity affect the investor's decisions. For this reason coherent investors claim higher returns on stocks which are less liquidity.

Harry Markowitz presented a model in 1958 known as CAPM, which is used to measure the relationship between stock returns and risk. Well along Sharp and Linter (1964) and Black (1972) formerly presented a model which is used to measure risk premium and risk free rate and they also incorporated Beta factor which measure the stocks return sensitivity. Initially many research have been conducted where number of different methods of liquidity was adopted to check the relationship with stock returns. This illustrate that there are number of illiquidity causes that are asymmetric information, demand pressure, inventory risk and exogenous trading costs. Henceforth these cost will charge to the investor on holding assets which resultantly demand higher premium return.

The primary objective is to analyze the associationamong liquidity and stock returns. In Pakistan there are few studies that have been conducted on this area. So, this study will help to determine the effect of liquidity on stock return in Pakistan.

The significance of the study is that there are very less number of work done on this area. So to sightseethe association among liquidity and stock returns in developing country we opted this topic. There are other researcher that are conducted on same problem but different countries and each and every author came up with different results. Developed countries are still making developing countries part of their research because every time they explore new determinants of stock return which provide new aspect of research. The liquidity and stock returns are still under debate because with so many research all over the world researcher could not came up with full picture. So we are trying to elucidate the impact of liquidity with stock returns in Pakistani markets. This research will help both academia and practitioner's because it will help them to use for further research and considering other factors for measures stock returns respectively.

\section{Research Questions}

To measure the impact of liquidity on stock returns, there should be some research question which will be addressed and i.e.; to what extent there is relationship amid stock returnsand liquidity. 


\section{Literature Review}

Many studies has been done on liquidity and stock returns but Amihud and Mendelson (1986)took intuitive and examined the relationship for the very first time, they found the liquidity mark as the cost of instantaneous implementation. They also explained that ask-bid spread covers a premium in it instantaneous sale or purchase, and also that spread between demand and supply is normal measure of illiquidity. Amihud and Mendelson (1986) also investigated that there is and increase and concave relationship between illiquidity and rate of return in an equilibrium point. They also explained that there is a negative correlation between financial assets spread and trading volume and shareholders number (characteristic of liquidity). Whereas, there study also incorporated that asset return will increase if the ask-bid spread will increase.

Brennan and Subrahnanyam (1996) investigated that measuring illiquidity is very crucial as compared to ask-bid spread because it contain information symmetry factor. Some researchers explained new measures of illiquidity by disintegrating transaction cost into two components. Theoretical framework of previous researchers shows that liquidity and information asymmetric frequently measured through transaction costs (Kyle, 1985; Glosten, 1989; Glosten\& Harris, 1988 and Esaley and O’Hara, 2002).

Amihud (2002)investigated the relationship between illiquidity and rate of return which was defined by Fama and MacBeth (1973). Another research conducted by Pastor and Stambaugh (2003) that liquidity and stock price fluctuations are due to the volume or order flows. They also offered another measure of liquidity by reversing the price to measure the degree of market liquidity. Furthermore, the larger the expected price reversal, lower will be the stock liquidity (Pastor and Stambaugh, 2003).

When the premium on liquidity is higher than the return will also be higher. The relationship ask-bid spread and liquidity is qualitatively same during the all months of the year (Hamon and Jacquillat, 1997). Moreover, Amihud (2002) stated that expected return is an increasing trend in illiquidity whereas to test this hypothesis author came up with new dimension which was elucidated by Fama and MacBeth (1973). They presents significant and strongly positive relationship with illiquidity and stock returns despite the fact that transaction cost is negatively correlated with returns.

Furthermore, some researchers indicated the negative associationamong liquidity and stock returns (Spiegel and Wang (2005) and Chang et, al (2010)). Whereas, some researcher indicated the positive association among liquidity and stock returns which actually differingfrom previous researches (Yakov and Mendelson (1986); Chan and Faff in (2005) \&Archaya and Pedersen (2005)).

Marshall and Young (2003) conducted study on impact of liquidity and stock returns and they introduced three measures of liquidity that are, rotation ratio, ask-bid spread and amortized ask-bid spread. They concluded negative association among spread and returns. Moreover, they find significant negative relationship between financial asset returns and rotation ratio, however amortized spread does not show no significance.

\section{Methodology}

In this study we explained the impact of liquidity on stock returns of Pakistan market. Sample of the study was 10 listed companies of Karachi Stock Exchange (KSE). We collected the data through convenience sampling. The data was gathered from 2005 to 2012. All secondary data was gathered from Karachi Stock Exchange, State Bank of Pakistan websites. Following are the companies that were used as sample of this study; Pakistan Tobacco Company Limited, Pakistan Oil Field Limited, Pakistan Petroleum Limited, Lotte Pakistan PTA Limited, Jahangir Siddiqui Co Ltd, Nishat Mills Limited, Pakistan State Oil Company Limited, Thal Limited, Lucky Cement Limited, Pakistan Oil Field Limited, Oil and Gas Development Company Limited. Companies stock returns was calculated by using return formula i.e. $\mathrm{Ln}(\mathrm{Pn} / \mathrm{Pn}-1)$. Whereas natural $\log$ is denoted by Ln, Current price is denoted byPnand lag price is denoted by Pn-1. Sample companies Beta was calculated by using the following formula:

\section{$\beta=$ Covariance $(\mathbf{R t}-\mathbf{R m}) /$ Variance $(\mathbf{R m})$}

To determine the market return, KSE-100 index can be used as proxy variable to calculate the average $\log$ return. To collect the risk free rate, State bank of Pakistan (SBP) website was used. Excess return was calculated by using below mentioned formula:

\section{Excess return $=$ Stock return - Risk free rate}

In this study excess return was used as independent variable with market premium and risk free rate. To measure the liquidity, Ask-bid spread was used as proxy variable. Capital asset pricing model (CAPM) was used to measure the relationship between liquidity and stock returns. So:

$\mathbf{R}_{\mathrm{i}}=\mathbf{R}_{\mathrm{f}}+\boldsymbol{\beta}\left(\mathbf{R}_{\mathrm{m}}-\mathbf{R f}_{\mathrm{r}}\right)$ 
While stock return was denoted with Ri, risk free rate of security was denoted with Rf, stock beta was denoted by $\beta$ and last but not the least market return was denoted with $\mathrm{Rm}$.

Furthermore, when Ask-bid spread was incorporated in regression equation then:

$\mathbf{E}(\mathbf{R i})=\mathbf{R f}+\boldsymbol{\beta}\left\{\mathbf{E}\left(\mathbf{R}_{\mathrm{m}}\right)-\mathbf{R}_{\mathrm{f}}\right\}+\mathbf{f}\left(\mathbf{S}_{\mathrm{i}}\right)$

Thus, expected stock return was denoted by $\mathrm{E}(\mathrm{Ri})$, risk free rate was denoted by $\mathrm{Rf}$, stock Beta was denoted by $\beta$, market return was denoted by Rm and lastly Ask- bid spread was denoted by $\mathrm{Si}$.

To measure all the data regression and correlation was used to measure the impact of liquidity and stock returns. E-Views 7 was used to analyze the result which help to reach the conclusion.

\section{Data Analysis}

Data was analyzed through two stage regression. In first stage, we took excess return as independent variable and stock return as dependent variable (excluded of ask-bid spread, proxy of liquidity). Whereas, in second stage we took incorporated ask-bid spread as proxy of liquidity measure in the model. By using first stage regression, the result was depicted in table 1 . The result was insignificant like f-statistics and coefficient which explained the deficiency of appropriate aspects in the model. F statistics explained the model significance whereas, coefficient designates excess market return which is 0.079 percent of undiversifiable risk. This showed that there are some other aspects that explain the unsystematic risk. R square elucidated that $0.249 \%$ change in excess return was due to stock returns. Furthermore, adjusted R square explicated that by incorporating or deleting any variable that changes the value of $\mathrm{R}$ square by $0.156 \%$.

Table-1

\begin{tabular}{lllll}
\hline \hline Variable & Coefficient & Std. Error & t-Statistic & Prob. \\
\hline \hline C (Constant) & -0.079449 & 0.044748 & -1.775480 & 0.1137 \\
BETA & -0.497749 & 0.304872 & -1.632646 & 0.1412 \\
\hline \hline R-squared & 0.249920 & Mean dependent var & -0.134568 \\
Adjusted R-squared & 0.156160 & S.D. dependent var & 0.101107 \\
S.E. of regression & 0.092878 & Akaike info criterion & -1.738204 \\
Sum squared resid & 0.069011 & Schwarz criterion & -1.677687 \\
Log likelihood & 10.69102 & Hannan-Quinn criter. & -1.804591 \\
F-statistic & 2.665534 & Durbin-Watson stat & 2.480799 \\
Prob(F-statistic) & 0.141187 & & \\
\hline \hline
\end{tabular}

The simple equation is regressed in Eviews

In table 2, when ask-bid spread was incorporated in the model, results became significant. F statistics probability was less than $0.05 \%$ which is significant whereas, coefficient of liquidity was negatively displayed in the results. This portrayed that impact of stock return has negative relationship with liquidity. $\mathrm{R}$ square value showed $0.735 \%$ but still there are many other attribute that can describe the excess return.

Table-2

\begin{tabular}{lllll}
\hline \hline Variable & Coefficient & Std. Error & t-Statistic & Prob. \\
\hline \hline C & 0.078227 & 0.052293 & 1.495930 & 0.1783 \\
BETA & -0.300371 & 0.201027 & -1.494185 & 0.1788 \\
SPREAD & -0.903951 & 0.251801 & -3.589941 & 0.0089 \\
\hline \hline R-squared & 0.735989 & Mean dependent var & -0.134568 \\
Adjusted R-squared & 0.660558 & S.D. dependent var & 0.101107 \\
S.E. of regression & 0.058907 & Akaike info criterion & -2.582394 \\
Sum squared resid & 0.024290 & Schwarz criterion & -2.491619 \\
Log likelihood & 15.91197 & Hannan-Quinn criter. & -2.681975 \\
F-statistic & 9.757042 & Durbin-Watson stat & 0.745042 \\
Prob(F-statistic) & 0.009455 & & \\
\hline \hline
\end{tabular}

The CAPM and Liquidity equation is regressed in Eviews 
Liquidity has a positive relationship with the stock returns when measured against the liquidity and beta valueweighted averages. The turnover rate gets affected from the bid-ask spread hence showing the positive relation. Fama-French factors also supported the above relationship. The portfolio formation process is also further enhanced by considering the association amongst the liquidity and returns of the stock giving equal weight to the stocks in portfolios in conclusion. To determine the association between stock return and liquidity, beta is the strongest measure. The relative ask-bid spread is considered as the proxy of liquidity prevailing as an outcome of analysis. This finding leads towards formation of portfolios by dividing risk as revealed by FamaFrench model. It is summarized that liquidity risk is clearly seen in Pakistan market which effects the stock pricing and increase the liquidity risk which ultimately attracts the premium. To overcome the limitations and further confirmed the results by increasing the sample size and time period.

\section{Conclusion}

The study is conducted to verify the relationship between the two variables that is liquidity and its impact on the stock returns. To know this, first the theoretical evidence was drawn which lead towards the empirical evidence. The sample was taken from the Pakistan stock Exchange. The cross sectional association among liquidity and stock return was analyzed. A comprehensive literature was reviewed for defining the liquidity in relation to the stock.

Liquidity is considered as trading of large quantity of stocks purchased as low cost without lowing the prices. Number of theoretical models represented both estimating liquidity and valuing of liquidity risk. The less liquid stocks cause the demand of the rational investor to get higher in case of returns as sensitivity towards the liquidity is considered as risk. Moreover, high risk is associated with returns by the investors.

The relationship of stock return and ask-bid spread was first presented by Amihud and Mendelson (1986). This model has greater importance in context of stock return and liquidity, they explained the stock returns have positive relationship with liquidity in US stock market. Whereas, our study concluded that both liquidity and stock returns have negative relationship which was supported by (Pereira \& Zhang, 2008; Salehi, Talebina\&Ghorbani, 2011).

\section{Limitations and Future Research directions}

To further strengthen the results following shortcomings should be removed.

- Availability of extensive literature was the hurdle for conducting this study as limited research has been carried out in this topic.

- Secondary data is also not available for the Pakistan's context so to gain further insight and assessing the results.

- Liquidity is only variable studied here irrespective of many other factors affecting the stock returns which could be the part of the model to better understand the stock returns.

- Data is collected from KSE only irrespective of presence of other two stock exchanges of Pakistan which could be the part of the sample.

- To investigate the excess return in relation to stock sensitivity with variation of collective liquidity for future research.

- The same analysis can be done on other markets as on fixed income market, bond market, international equity markets etc. as well.

\section{Reference}

[1]. Amihud, Y. and H. Mendelson (1986), “Asset pricing and the bid-ask spread”. Journal of Financial Economics 17, $223-249$.

[2]. Archarya, V. V., and L. H. Pedersen (2005), "Asset pricing with liquidity risk". Journal of Financial Economics 77, 375-410.

[3]. Black, F. (1972), "Capital market equilibrium with restricted borrowing”. Journal of Business, 45 (3), $444-455$.

[4]. Brennan, M. J. and Subrahmanyam, A. (1996), "Market microstructure and asset pricing: on the compensation for illiquidity in stock returns". Journal of Financial Economics, 41, 441-464.

[5]. Chan, H. W. and R. W. Faff (2005), "Asset pricing and the illiquidity premium". The Financial Re- view 40, $429-458$.

[6]. Chang, Y. Y., Faff, R. and Hwang, C. Y. (2010), "Liquidity and stock returns in Japan: New evidence". Pacific Basin Finance Journal, 18, 90-115.

[7]. Easley, D. \& O’Hara M. (1987). Price, trade size and information in securities markets. Journal of Financial Economics, 19, 69-90.

[8]. Fama, E. F. and J. D. MacBeth (1973), "Risk, return and equilibrium: Empirical tests". Journal of Political Economy 81, 607-636.

[9]. Glosten, L R. \& Harris, L. (1988). Estimating the Components of the Bid / Ask spread. Journal of Financial Economics, 21, 123142.

[10]. Hamon, J. and Jacquillat, B. (1997), "Is there value added information in liquidity and risk premiums"? European Financial Management, 3, 369-393.

[11]. Kyle, A. (1985), 'Continuous auctions and insider trading', Econometrica, 53: 1315-1335.

[12]. Marshall, B. R. and Young, M. (2003), "Liquidity and stock return in pure order driven markets: evidence from the Australian stock market". International Review of Financial Analysis 12, 173-188.

[13]. Pastor, L. and Stambaugh, R. F. (2003), "Liquidity Risk and Expected Stock Returns”. Journal of Political Economy, 111: 642-685.

[14]. Pereira, J. P. and Zhang, H. H. (2010), "Stock Returns and the Volatility of Liquidity".Journal of Financial and Quantitative Analysis.

[15]. Sharpe, W. (1964), "Capital asset prices: A theory of market equilibrium under conditions of risk". Journal of Finance 19, 425-442. 